\title{
Influence of Altitude on the Spatiotemporal Variations of Meteorological Droughts in Mountain Regions of the Free State Province, South Africa (1960-2013)
}

\author{
M. Mbiriri $\mathbb{D}^{1,},{ }^{1,2,3}$ G. Mukwada, ${ }^{1,2}$ and D. Manatsa ${ }^{1,2,3}$ \\ ${ }^{1}$ Department of Geography, University of the Free State, QwaQwa Campus, P. Bag X13, Phuthaditjhaba, South Africa \\ ${ }^{2}$ Afromontane Research Unit, University of the Free State, QwaQwa Campus, P. Bag X13, Phuthaditjhaba, South Africa \\ ${ }^{3}$ Department of Geography, Bindura University of Science Education, P. Bag 1020, Bindura, Zimbabwe
}

Correspondence should be addressed to M. Mbiriri; getrudembiriri@gmail.com

Received 3 August 2017; Revised 15 November 2017; Accepted 21 December 2017; Published 22 January 2018

Academic Editor: Anthony R. Lupo

Copyright (c) 2018 M. Mbiriri et al. This is an open access article distributed under the Creative Commons Attribution License, which permits unrestricted use, distribution, and reproduction in any medium, provided the original work is properly cited.

\begin{abstract}
The Standardized Precipitation Index (SPI) was computed for October to December (OND) and January to March (JFM) summer subseasons for Free State Province, South Africa, to assess the influence of altitude on drought severity and frequency. The observed spatiotemporal heterogeneity in the SPI variability revealed that factors governing drought interannual variability varied markedly within the region for the two subseasons. Strong correlations between $r=0.76$ and 0.93 across the clusters in both subseasons were observed. Significant shift in average SPI, towards the high during the OND subseason, was detected for the far western lowlying and central regions of the province around the 1990s. An ANOVA test revealed a significant relationship between drought severity and altitude during the OND subseason only. The impact of altitude is partly manifested in the strong relationship between meridional winds and SPI extremes. When the winds are largely northerly, Free State lies predominantly in the windward side of the Drakensberg Mountains but lies in the rain shadow when the winds are mostly southerly. The relationship between ENSO and SPI indicates stronger correlations for the early summer subseason than for the late summer subseason while overall presenting a diminishing intensity with height over the province.
\end{abstract}

\section{Introduction}

Climate change impacts have been well recognized by researchers, environmentalists, and politicians [1-3]. The recurrence of extreme climate events has been identified as evidence of climatic change [4]. Studies in America [5], Europe [6], and Asia [7] have been done to examine the prevalence of extreme climate variables. In Africa, similar studies have been done in the north and central parts of the continent $[8,9]$ but with little attention given to the south. Southern Africa is regarded as semiarid with high annual rainfall variability that has drought as a common feature [10]. The impact of drought is ranked top compared to other natural disasters [11]. While several studies have been done on climate variability in terms of rainfall, contrasting results have been observed especially for semiarid regions [3]. Research studies that have been done on high elevation areas since the 1990s have concluded that climate change will severely affect the mountain regions of the world $[12,13]$. For example, the frequency of extreme droughts has increased in the mountainous regions of Northeast and North China [7]. In recognition of this reality, the United Nations Secretary General declared the year 2002 "The International Year of Mountains." In face of climate change, mountain biota will suffer the most, as it is adapted to relatively narrow ranges of precipitation and temperatures [14]. Studies on mountain regions are slowly gaining attention in other parts of the world such as America [15], Asia [16], and slowly Africa [12, 17].

A number of drought indices have been developed to understand drought. A drought index is a quantitative measure that characterizes drought levels by assimilating data from one or several indicators, for example, precipitation [18]. Among the most widely used indices are the Palmer Drought Severity Index (PDSI), Crop Moisture Index, and the Standardized Precipitation Index (SPI) [19]. SPI has become popular due to simplicity in its calculation, as it only requires 
rainfall data. It also allows for the detection of various types of drought that affect different systems and regions while enabling calculation of estimates of the duration, magnitude, and intensity of drought [20]. Agricultural drought, also known as soil moisture drought, exists when the available soil moisture is insufficient to sustain the crops and forage resulting in a decrease in agricultural productivity [21]. While SPI is designed for meteorological droughts, it can also be used to detect agricultural drought when calculated on a short time scale since soil moisture conditions respond to precipitation anomalies on a relatively short scale [21]. On longer time scale (say 12 or 24 months), it is more suitable for water resources management purposes. The SPI is based on the probability of precipitation occurrence over a given time period. Since precipitation is not normally distributed, a mathematical transformation is applied so that the transformed precipitation values follow a normal distribution. It is after this transformation to normal distribution that the classification of frequencies of the extreme and severe droughts experienced at any location and timescale becomes consistent [20]. The SPI, however, like any other index, has its limitations; it does not take into account the contribution of other variables to drought severity, for example, the atmospheric evaporative demand [22]. In addition, SPI does not provide reliable estimations in arid climates [23]. Despite these shortcomings, the SPI remains one of the most widely used and acceptable indices in climate research, with its tried and tested effectiveness in decision making [24].

Understanding the climatic conditions in mountain regions is not only important for agriculture but for biodiversity studies also, since life in the mountains is not driven by elevation per se but by the climatic conditions associated with elevation [25]. In this study, the only part of the mountain range that lies within the political borders of Free State Province was considered in order to provide a comparative analysis between mountainous (to the east) and low-lying areas located to the west of the province. An indepth analysis of mountain related intensity, frequency, and spatial extent of extreme droughts at a higher resolution is necessary for a more comprehensive assessment of drought impacts. This work focused on short term meteorological droughts (3-month SPIs for December and March) because they can serve as proxies for agricultural droughts which are important in the Free State Province. Understanding these droughts will be critical for understanding the resilience of the region in the future. Hence, the objective of this study is to analyze severe to extreme drought as well as severe and extreme wet conditions in mountain regions of southern Africa, with particular emphasis on the Drakensberg Mountains within the borders of the Free State Province of South Africa for the period between 1960 and 2013.

\section{Materials and Methods}

2.1. Study Area. The study area is confined to the political borders of the Free State Province of South Africa (Figure $1(\mathrm{a}))$. The province is situated between latitudes $26.6^{\circ} \mathrm{S}$ and $30.7^{\circ} \mathrm{S}$ and longitudes $24.3^{\circ} \mathrm{E}$ and $29.8^{\circ} \mathrm{E}$ and sprawls over high plains which stretch over the Maluti-Drakensberg Mountains along the border with Lesotho. The Drakensberg Mountains cover approximately $1,125 \mathrm{~km}^{2}$ and reach heights of over 3,475 metres above sea level. It is South Africa's main watershed and is the source of the Orange River, one of the major sources of water supply for commercial agriculture in the country. The province covers an area of $129,825 \mathrm{~km}^{2}$. The climate of the Free State Province is highly influenced by the geographic location, which is continental and is characterized by warm to hot wet summers and cool to cold dry winters. The rainfall season spans from October to March. Greatest amounts are received in January and February, giving the JFM subseason more average total precipitation than the OND subseason, with 56 percent contribution towards the seasonal total precipitation. A west to east seasonal monthly average precipitation increase has been observed over the province with the extreme west receiving a monthly average of not more than $50 \mathrm{~mm}$ while the extreme east receives an approximate of over $100 \mathrm{~mm}$ during the October to March period (Figure $1(\mathrm{~b})$ ).

2.2. Data. Monthly mean precipitation ( $\mathrm{mm}$ ) covering the 1960-2013 period was extracted from Climate Explorer's Climate Research Unit (CRU TS4.01) gridded data file at $0.5^{\circ} \times 0.5^{\circ}$ spatial resolution (available from https://climexp.knmi.nl). The wind data was downloaded from ERA-interim (Resolution T255), which is currently the largest global atmospheric reanalysis dataset and produced by the European Centre for Medium-Range Weather Forecasts (ECMWF). The analysis was done online using Climate Explorer. These data products are principally derived from observations in line with the World Meteorological Organization guidelines and are freely available online. In many developing countries observational data with required data lengths and quality are unavailable [29]. It is because of this limitation that the use of reanalysis data has gained popularity within the climate science field. Several studies have shown that while the use of these datasets may not be as accurate as station data, the difference is insignificant in many of the cases [30]. The period of 53 years meets the minimum climatic analysis duration requirement outlined in the World Meteorological Organization guidelines [31].

A total of 107 grid points was used in the analysis covering the Free State Province. The grid points in the immediate borders of the province were also included as the influence of these points contributes to the overall climate characteristics of areas within the province (Figure 2). The province was divided into three homogenous subregions or clusters based on altitude. This was done using Hot Spot Analysis (HSA) in an ArcGIS (version 10.3) environment. The use of special analyses such as HSA helps in identifying groups of locations with high spatial homogeneity and it has been shown that such segregation may significantly increase the quality of interpolation results [32]. Cluster analysis does not require a priori knowledge on data structure such as normality condition as required in other statistical tests [33]. 


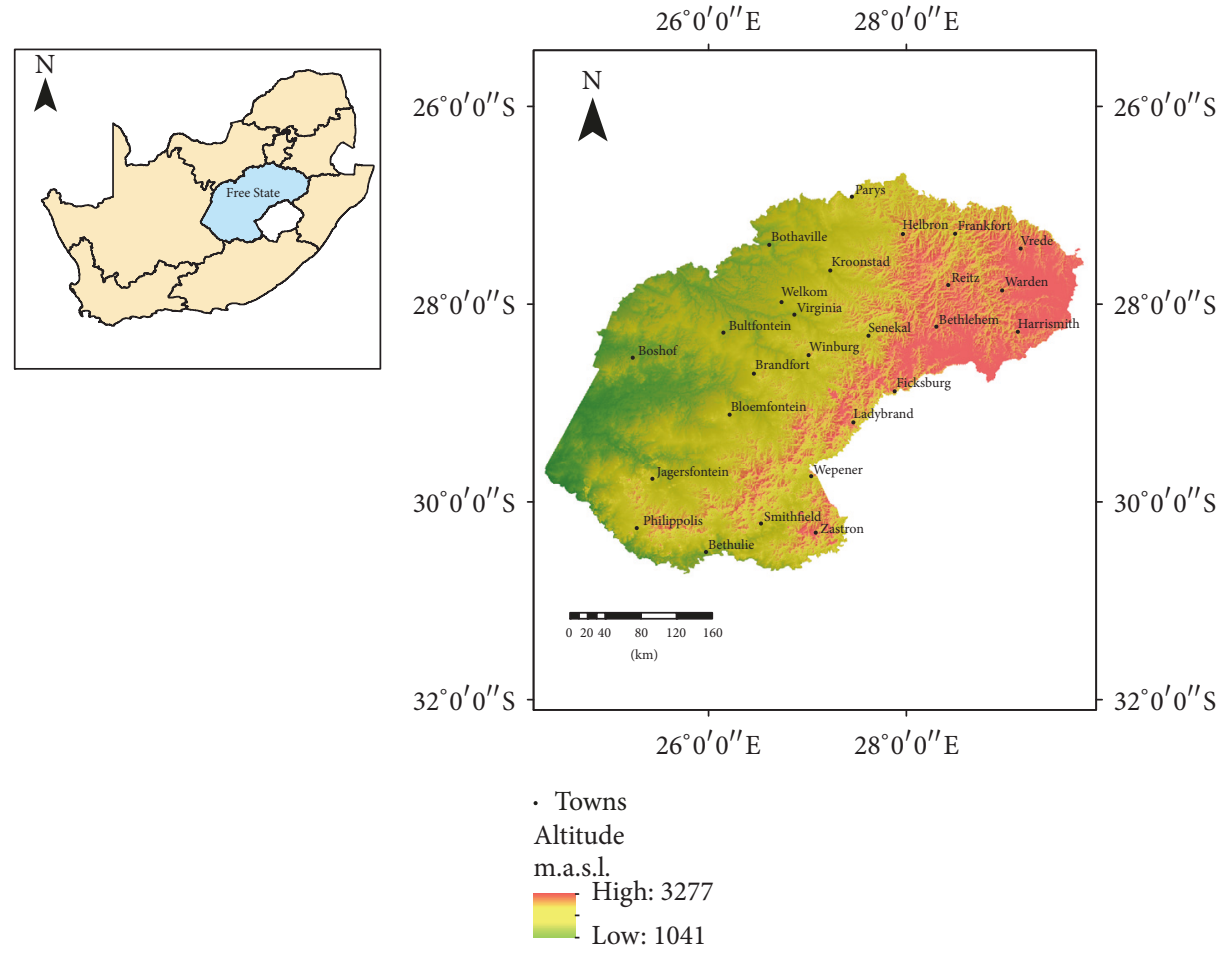

(a) Location of the Free State Province in South Africa

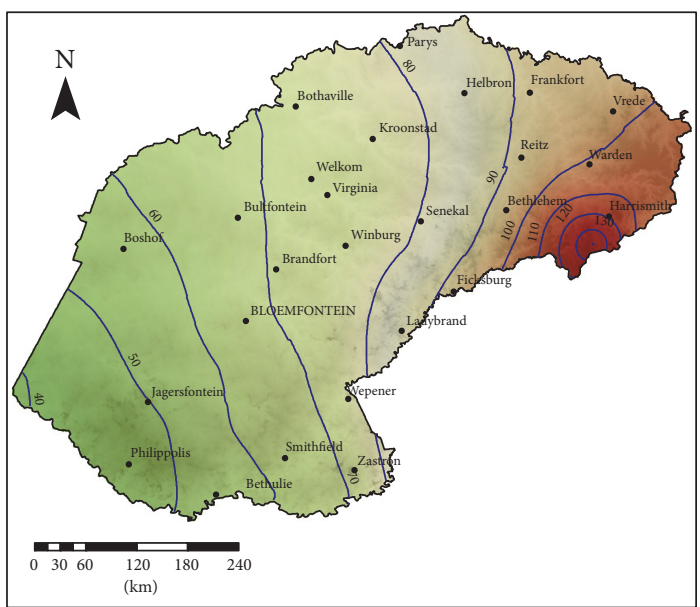

_ Average precipitation Elevation m.a.s.l. precipitation $\mathrm{mm}$

C. High: 3277

Low: 1041

$=$ High: 140.3
Low: 38.9

$\square$ Provincial Boundary

(b) Distribution of seasonal monthly average precipitation (October-March) for Free State Province in South Africa. The data is from 1960 to 2013

FIGURE 1

HSA is a local spatial pattern analysis tool which works by considering each feature within the context of neighbouring features and determines if the local pattern (a target feature and its neighbours) is statistically different from the global pattern (all features in the dataset). The $Z$-score and $p$ value results associated with each feature determine if the difference is statistically significant or not. Hence, this variable could potentially improve the results of other interpolation techniques when used instead of elevation as an auxiliary variable. The clustering by HSA enables the comparison of 
TABLE 1: Categorization of dryness/wetness.

\begin{tabular}{lcc}
\hline SPI value occurrence & \% occurrence & Nominal SPI class \\
\hline$\geq 1.645$ & $\leq 5$ & Extremely wet \\
1.282 to 1.644 & $6-10$ & Severely wet \\
0.842 to 1.281 & $11-20$ & Moderately wet \\
0.524 to 0.841 & $21-33$ & Slightly wet \\
-0.523 to 0.523 & $34-50$ & Normal \\
-0.841 to -0.524 & $21-33$ & Slight drought \\
-1.281 to -0.842 & $11-20$ & Moderate drought \\
-1.644 to -1.282 & $6-10$ & Severe drought \\
$\leq-1.645$ & $\leq 5$ & Extreme drought \\
\hline
\end{tabular}

Adapted from [26] and modified by [27] to enhance suitability for application in southern Africa. The original classification was developed by [28].

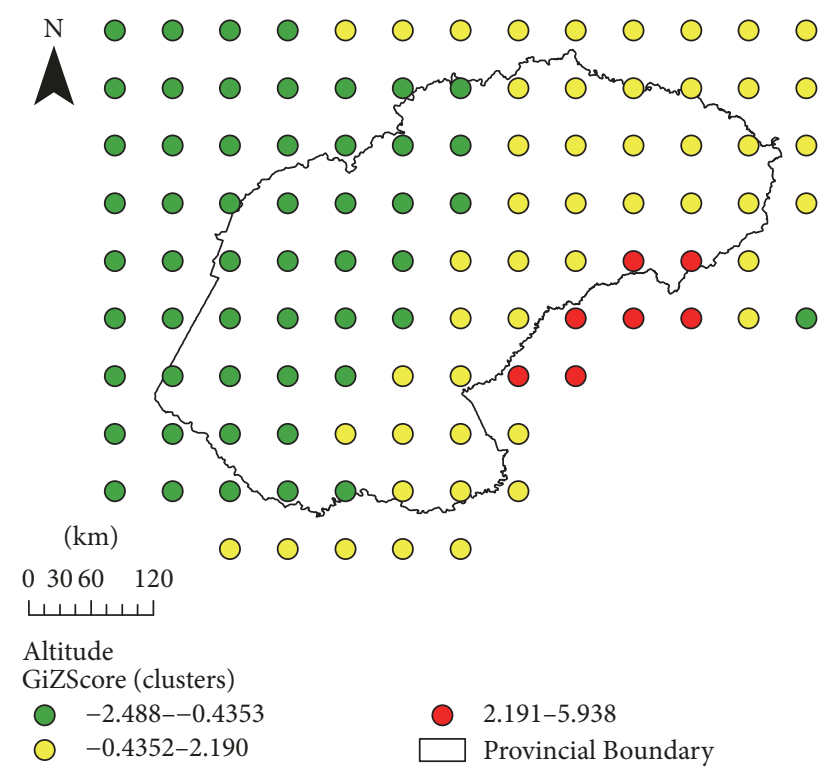

Figure 2: Locations of clusters in the Free State Province (Cluster 1 (green), Cluster 2 (yellow), and Cluster 3 (red)).

droughts and wet characteristics of the different areas within the province. Further, the Inverse Distance Weighting (IDW) method of interpolation was used in preparing the frequency maps. The IDW technique assumes that each measured point has a local influence that diminishes with distance; thus it gives an output surface that is sensitive to clustering and the presence of outliers.

Monthly precipitation values were used to compute SPIs at 3 months' scale, for periods January-March and October-December using Drought Index Calculator (DrinC). The distinct climate controls of the subseasonal rainfall in southern Africa warranted that the analysis be done by splitting October-December from January-March. During October to December, usually regarded as early summer, the atmosphere has a predominant extratropical nature with frequent cut-off lows [34]. In January and February, tropical circulation systems are much more prevalent over South Africa with local convection dominating [35]. The two subseasons were arranged for analysis in such a way that OND_SPI for 1960 matched JFM_SPI for 1961. This is because the rainfall season overlaps two calendar years; thus, the continuous season of October-March is split into October-December of the previous year (1960) and January-March of the following year (1961). To avoid splitting the precipitation season, the meteorological year in southern Africa starts in July and ends in June of the following calendar year and hence is usually referred to as a season 1960/61. In this study, the subseasons were analyzed separately. Trends in the two subseasons were studied using parametric tests for these are regarded as more powerful especially for data that is regarded as independent and normally distributed [36].

2.3. Computing SPI. The SPI was calculated using monthly precipitation data for 53 years (1960-2013) following detailed procedure described by [28] and expressed using the formula

$$
\mathrm{SPI}=\frac{x_{i}-\bar{x}}{s}
$$

where $x_{i}$ is the monthly rainfall amount, $\bar{x}$ is the mean, and $s$ is the standard deviation of rainfall calculated from the whole time series of monthly values.

Using the SPI classification by [27] (Table 1), only severe to extreme droughts (SPI $\leq-1.282)$ were analyzed so as to amplify the drought signal.

Frequencies of drought years and the proportion of at least severe drought years in the two subseasons in the three individual clusters were calculated. $(N)$ represents the total count of drought years from slight drought to extreme drought. The percentage frequencies were calculated as follows:

$$
\begin{aligned}
& \text { Frequency }(\%) \\
& \begin{aligned}
= & \frac{\text { Number of severe (extreme) drought years }}{\text { Total number of drought years in } 53 \text { years }} \\
& \times 100,
\end{aligned}
\end{aligned}
$$

where drought is the total count of SPIs $\leq-0.524$.

To determine how drought severity is linked to altitudinal variability we applied the composite analysis technique. We extracted the five worst drought years of at least SPI $\leq-1.282$ 


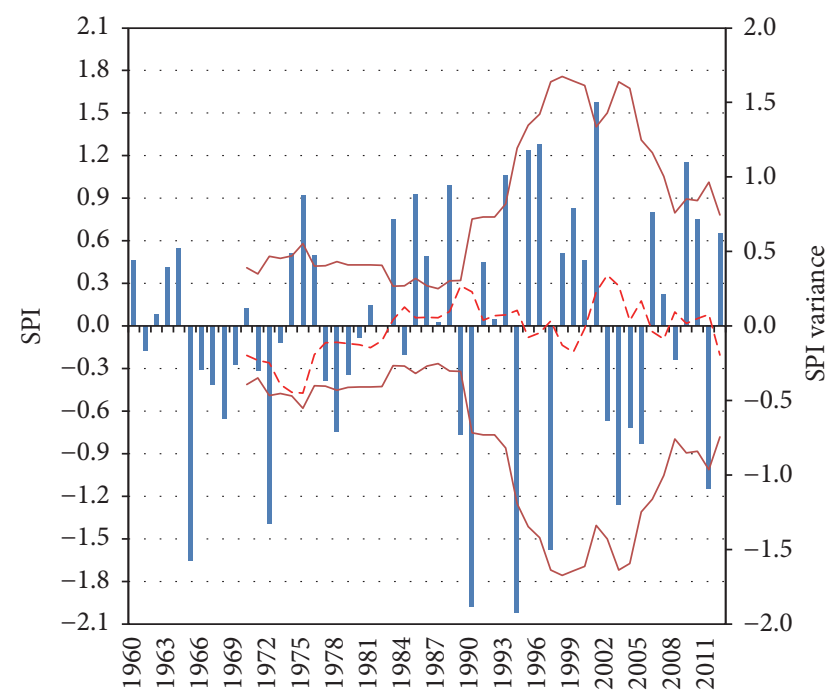

(a)

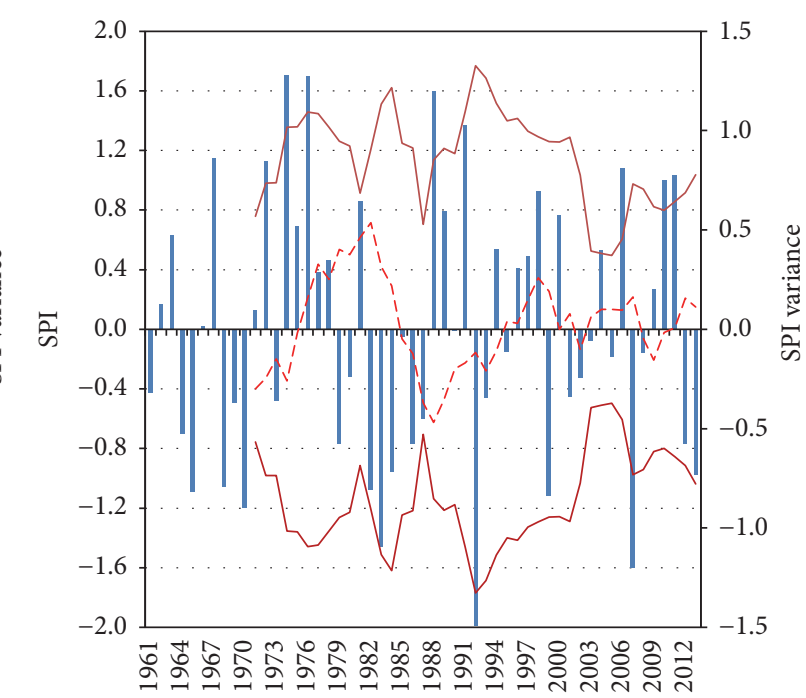

(b)

FIGURE 3: Temporal manifestation of the SPI (bars) for (a) OND and (b) JFM at provincial level. In the insert are the 10-year running variance envelope (solid lines) and mean (dashed line). The SPI is from 1960 to 2013.

at provincial scale. The years comprised 1965, 1972, 1990, 1994, and 1997. Averages for each of the clusters were plotted for the five severe drought years.

\section{Results and Discussion}

3.1. Temporal Variations of Drought Intensity in the Free State Province. Using grid point data, average SPIs were calculated for the whole province to give the provincial average SPI and for individual clusters. The inclusion of provincial scale was done to enable comparison of droughts (wet) years at provincial scale with those at cluster scale. This would assist in determining the ideal spatial scale to use for drought preparedness and response for the region. Figures 3(a) and 3(b) illustrate the temporal evolution of the SPI at provincial level for OND and JFM, respectively. For the OND subseason, severe drought years (SPI $\leq-1.282)$ were $1994(-2.023), 1990$ $(-1.974), 1965(-1.653), 1997(-1.580)$, and $1972(-1.393)$ while the wettest year (SPI $\geq 1.282)$ was 2001 (1.575). A shift to higher variance in the ten-year running variance (red line) is confirmed as a statistically significant shift in variance by the Sequential Regime Shift Detector (SRSD) which has a $p$ value of 0.002 in the early summer subseason (OND). This systematic pattern in variance could represent a coherent influence from an external large-scale process. The 10-year running mean (dashed line in Figure 3) indicates that on average the pre-1980s were characterized by rainfall deficits while the post-1980s period had predominantly surplus rainfall. However, it is during the latter period when the worst two droughts occurred in 1990 and 1994.

During the JFM subseason, severe droughts (SPI $\leq$ $-1.282)$ were experienced in $1992(-1.990), 2007(-1.601)$, and 1983 (-1.459). The severe wet years (SPI $\geq 1.282)$ experienced during the same subseason were 1974 (1.706), 1976 (1.699), 1988 (1.600), and 1991 (1.366). There appears to have been a shift to a wetter epoch after 1987 though the period is punctuated with more extreme droughts. From the 10year running variance (solid line), it can be noted that the interannual variability of SPI for JFM in Figure 3(b) is less variable and the SRSD indicates that the period is devoid of any significant shift. Thus, between 1960 and 2013, more severe drought (count) conditions were experienced during the OND subseason than during the JFM subseason; five (5) years against three (3) years while more severe wet years were experienced during the JFM subseason than during the OND subseason. A two-tailed paired samples $t$-test revealed that there is a significant difference between OND and JFM drought/wet magnitude for the 53 years' period. The JFM subseason has more intense droughts/wet conditions than OND subseason $t(49)=6.727$ and $p \leq 0.05$. It can be noted that the manifestation of the SPIs in the two subseasons differs markedly which indicates contrasting processes responsible for the droughts development within the subseasons.

The 10-year running mean demonstrates that the decades before the early 1990s had epochs of successive drought and wet years before oscillating around the mean thereafter. On the overall it is noted that the region is marked by droughts whose magnitudes have intensified in the last three decades. Since the JFM SPI patterns appear to be more random, we are more inclined to investigate further the OND period in search of less complex systematic drivers of the regional extreme events. It appears there is no clear-cut reason for the occurrence of wet or dry extremes in the region during JFM and hence it is likely that more local factors, which are not simple to identify in the absence of modeling, play a major role.

The local relationships to the SPI interannual and spatial variability of the Free State are still largely unknown. However, SPI values are dependent on a combination of several unrelated factors, such as number of rainfall events 


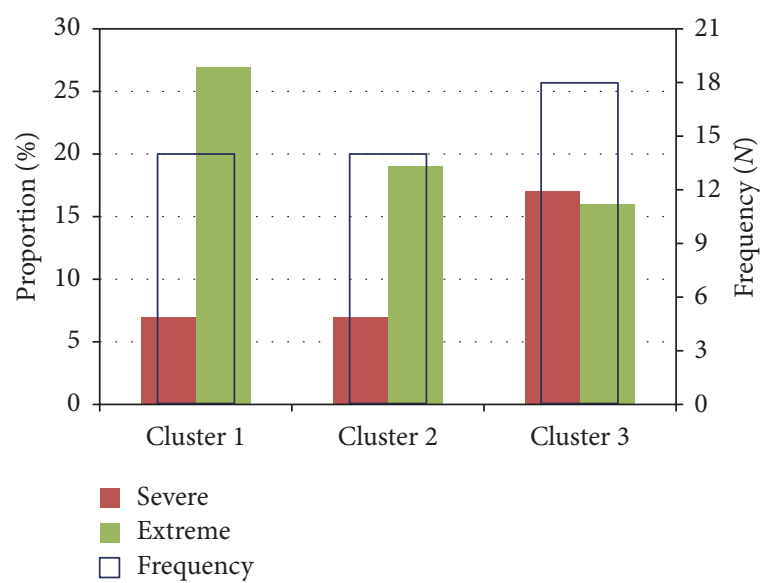

(a)

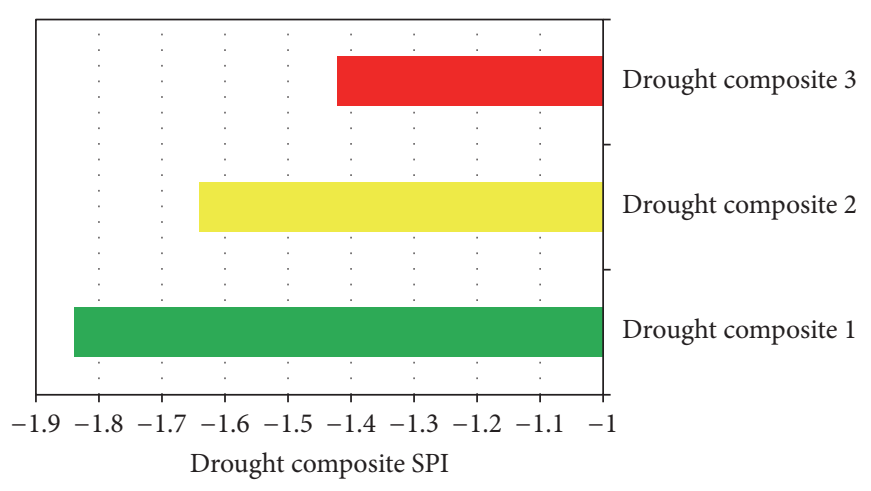

(b)

Figure 4: (a) Proportion of severe (extreme) droughts to total drought frequencies (SPI $\leq 0.524$ ) and (b) composite SPIs for Clusters 1, 2, and 3 during the OND subseason. The composite years are 1965, 1972, 1990, 1994, and 1997.

and their intensity and the onset and cessation of the season. An outstanding characteristic of the Free State region is its extreme spatial heterogeneity in SPI. It could be assumed that the heterogeneity is a result of the complex topography of the region that is largely shaped by the western parts of the Drakensberg Mountains. It is therefore interesting to investigate how this topography influences the drought signal throughout the region.

The three clusters obtained from HSA were maintained for the rest of the analysis and were used to assess the differences in drought evolution between low-lying areas and mountain regions in the southern part of Africa. Severe drought years at provincial scale between 1960 and 2013 were selected only for the OND subseason so as to show the variation in drought intensity for each of the clusters. This is because the JFM subseason is devoid of any significant shift in SPI as well as a well-defined pattern of variability. From Figure 4(a), Cluster 3 has the highest drought frequency and the highest percentage of severe droughts while Clusters 1 and 2 both have equal frequencies and proportion of severe droughts but lower than those experienced in Cluster 3. Thus, although Cluster 3 recorded the highest frequency of droughts, more extreme droughts occurred in Cluster 1 . The severe droughts proportion is increasing with cluster while the extreme droughts are decreasing. The $t$-test results for the significant difference between droughts of adjacent clusters revealed that although there are no significant differences between the adjacent clusters' composites, Clusters 1 and 3 show a significant difference with $p=0.1054$ ( $90 \%$ confidence level). Figure 4(b) shows the distribution of drought severity in the three clusters in the composite years summarized in Figure 4(a). The composite years for the three clusters are 1965, 1972, 1990, 1994, and 1997. Drought severity decreases with increasing altitude, a transition from Cluster 1 to Cluster 3 during the OND subseason only. None was observed during the JFM subseason. However, Cluster 2 experienced the most intense droughts in $3 / 5$ years of the worst drought years at provincial level. The variation of drought intensity with cluster indicates that the droughts are not evenly distributed in a season and could have their evolution strongly influenced by relief.

To measure the association of the SPI records in the three clusters during the OND subseason, linear correlation coefficient, $r$, was calculated. Pearson correlations of the SPI among the three clusters for the OND subseason show that there is a significant positive relationship between Cluster 1 and Cluster $2\left(r=.895^{* *}\right)$, Cluster 1 and Cluster 3 $\left(r=.763^{* *}\right)$, and between Cluster 2 and Cluster $3(r=$ $\left..894^{* *}\right)$. This result implies that dry/wetness variations in all the clusters are highly correlated. It clearly shows that the relationship between clusters is weaker and more varied for OND, an indication of weaker spatiotemporal homogeneity. SRSD found a statistically significant shift in SPI variance in Clusters 1 and 2 around $1990(p=0.000$ and $p=$ 0.003 , resp.) during the OND subseason (Figure 5). While there is a strong positive correlation between the clusters, the result of the distribution of the differences between the paired clusters (paired differences) shows that there is no statistically significant difference between the pairs during the JFM subseason.

The spatial distribution of drought frequencies in the two subseasons is shown in Figure 6. The figure shows hot spots for drought $(\mathrm{SPI} \leq-1.282)$ years during the two subseasons. The highest frequency of droughts is concentrated within the central belt of the province, giving a more horizontal belt of areas most prone to droughts of great intensity during the early summer subseason (Figure 6(a)). This suggests further investigation into the identification and analysis of the factors that may be contributing to increased vulnerability of these areas to severe droughts during the OND subseason. Common conditions known to bring aridity are associated with anticyclonic conditions but usually their spatial scales of influence are too large to account for the differing drought conditions within Free State. During the JFM subseason, 


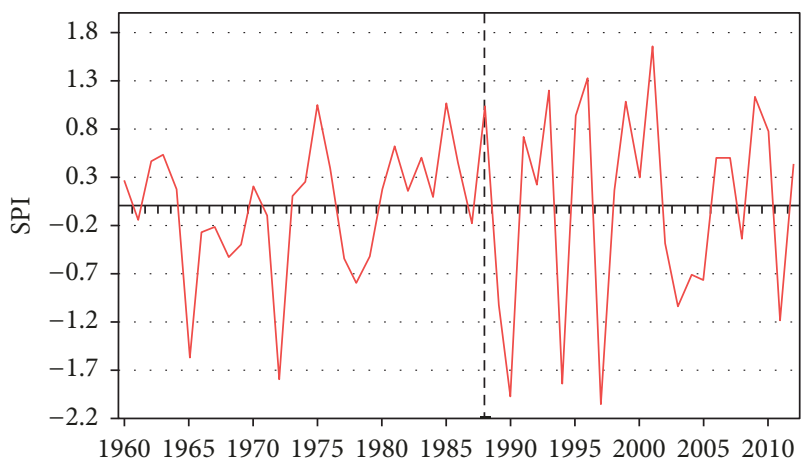

(a)

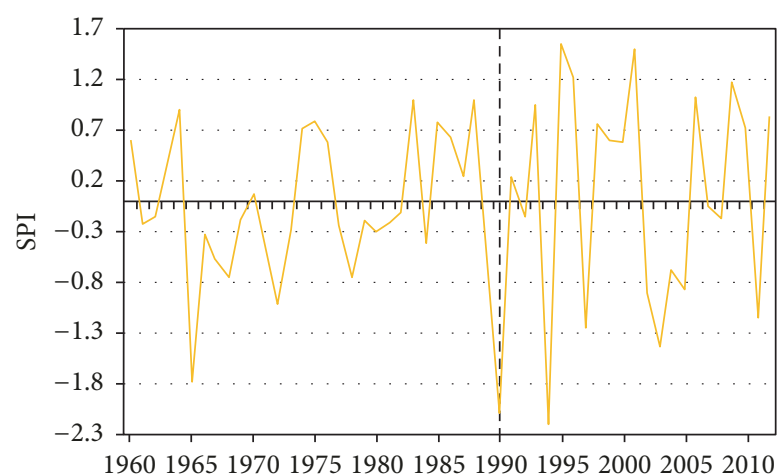

(b)

FIGURE 5: Temporal manifestation of SPI with results of the SRSD superimposed to show the shift in the variance (dashed line) for (a) Cluster 1 and (b) Cluster 2 during the OND subseason. The data is from 1960 to 2013.

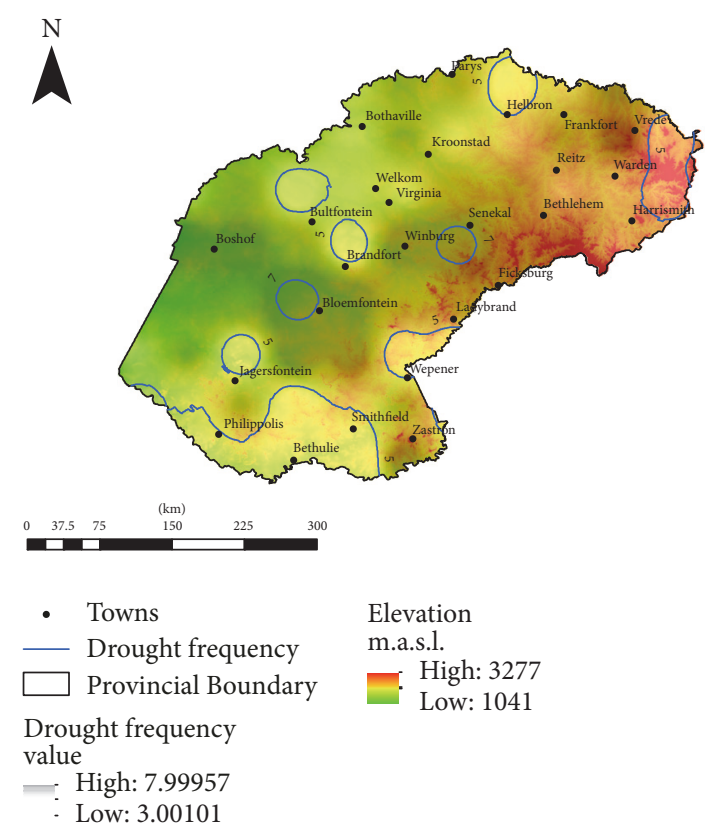

(a)
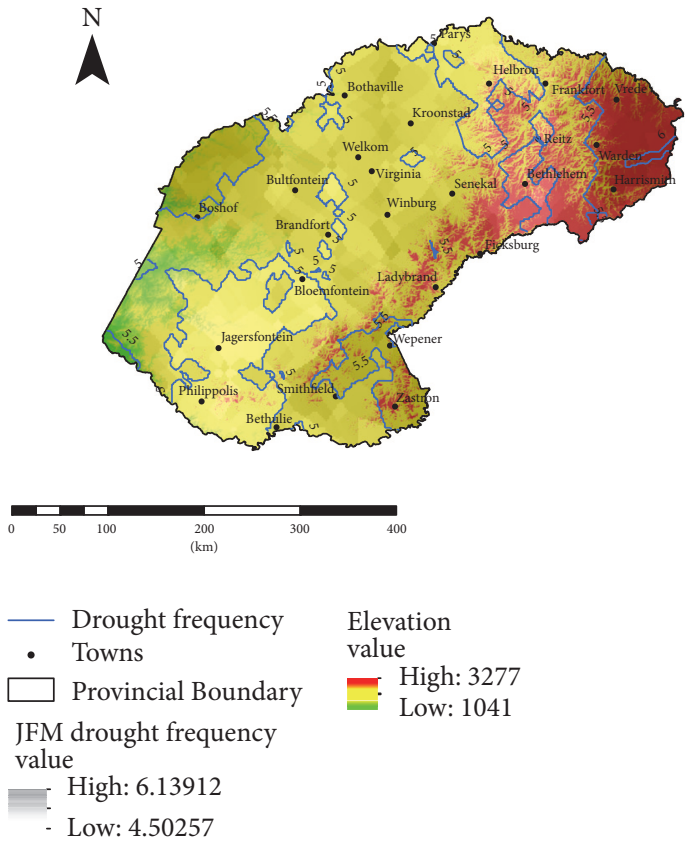

Elevation

value

=. High: 3277

FIGURE 6: Frequency of drought years (SPI $\leq-1.282$ ) for (a) OND and (b) JFM for the period 1960-2013.

however, the areas prone to severe droughts are to the extreme northeastern tip, the central west, and the extreme southeastern areas of the province (Figure 6(b)).

The influence of altitude on drought severity was tested using ANOVA. Results are shown in Table 2. The results show that altitude has significant influence on drought severity in the Free State Province in the OND subseason but not during the JFM subseason (in brackets). This influence is shown to be significant $\left(F_{\{\mathbf{8}, 2637\}}=2.54 ; p>0.01\right)$. This means that the OND droughts vary significantly with altitude while the JFM drought variations are not associated with variations in altitude, confirming that the systems that bring precipitation to the region are different. Those for the OND are altitude related while those for the JFM are not. This implies that relief rainfall, which is wind related, is a possible candidate to explain the relationship between droughts and altitude during the OND period.

Analysis of variance results on the altitudinal influence on drought/wet frequency reveal significance during the JFM subseason only for both severe drought and severe wet conditions (in brackets) (Table 3). This means that frequencies of JFM severe drought and wet episodes vary with altitude.

3.2. Wind Patterns Associated with Drought/Wet Events over Free State. Convection is less prominent during the OND period and hence relief rainfall should dominate the mountainous region of Free State. Moreover, since relief has been found to significantly impact on the subseasonal drought magnitude, then a more likely factor to affect the rainfall 
TABLE 2: Influence of altitude on drought severity for OND and JFM subseasons (in brackets).

\begin{tabular}{|c|c|c|c|c|c|}
\hline Altitude & Sum of squares & $\mathrm{df}$ & Mean square & $F$ & Sig. \\
\hline Between groups & $\begin{array}{c}669848.947 \\
(235716.673)\end{array}$ & 8 & $\begin{array}{c}83731.118 \\
(29464.584)\end{array}$ & $\begin{array}{l}2.536 \\
(.888)\end{array}$ & $\begin{array}{l}.009 \\
(.526)\end{array}$ \\
\hline Within groups & $\begin{array}{c}8706611.38 \\
(87500743.65)\end{array}$ & 2637 & $\begin{array}{c}33017.297 \\
(33181.928) \\
\end{array}$ & - & - \\
\hline Total & $\begin{array}{c}87736460.33 \\
(87736460.33)\end{array}$ & 2645 & - & - & - \\
\hline
\end{tabular}

TABLE 3: Influence of altitude on severe drought (wet) frequencies for JFM subseason.

\begin{tabular}{|c|c|c|c|c|c|}
\hline Altitude & Sum of squares & $\mathrm{df}$ & Mean square & $F$ & Sig. \\
\hline Between groups & $\begin{array}{c}964097.644 \\
(1072072.773)\end{array}$ & $\begin{array}{c}10 \\
(12)\end{array}$ & $\begin{array}{c}96409.764 \\
(89339.398)\end{array}$ & $\begin{array}{c}5.591 \\
(5.856)\end{array}$ & $\begin{array}{c}.000 \\
(.000)\end{array}$ \\
\hline Within groups & $\begin{array}{c}672483.237 \\
(564508.107)\end{array}$ & $\begin{array}{c}39 \\
(37)\end{array}$ & $\begin{array}{c}17243.160 \\
(15256.976)\end{array}$ & - & - \\
\hline Total & $\begin{array}{c}1636580.880 \\
(1636580.880)\end{array}$ & $\begin{array}{c}49 \\
(49)\end{array}$ & - & - & - \\
\hline
\end{tabular}

received at a particular place is its wind speed and direction. This is because these two parameters determine the amount of moisture carried by an air mass and the rate of relief forced adiabatic cooling which is subsequently translated to rainfall. This implies that a particular place can be in the rain shadow/windward side of the mountain depending on the prevailing wind average characteristics of that season. Therefore, in this section we analysed the wind characteristics for the drought and wet events to determine the extent of the wind impacts in defining the drought/wet spatial properties for selected seasons for the Free State Province.

The strong linkage between drought and altitude is an interesting observation (Table 2). Rain producing systems in the vicinity of the Drakensberg Region consist of two types [37]. The predominant sources of rainfall are largescale line thunderstorms and orographically induced storms. The former are more prevalent during the solar enhanced convection of the JFM subseason. As such, the latter are related to the surface wind characteristics like humidity, wind speed, and direction which should account for most of the rainfall during OND as this has a large bearing on the windward and rain shadow aspect of a particular place. In this regard, in Figure 7 we present the drought/wet composites in relation to the zonal and meridional anomalous winds at the near surface $(850 \mathrm{hPa})$. It is noted that the surface winds appear to be the most robust link to the drought and wet events during this subseason. Figure 7 indicates that, during drought, near surface winds are westerly (a) and northerly (b) with an anomalous high pressure having been built up to the west of the region (c). This is further illustrated in Figure 7 (c) where the vector winds are southeasterly over the Free State region that are driven by a low pressure anomaly situated to the southeast of the subcontinent as indicated by the geopotential heights. This is bound to advect relatively cold and relatively drier maritime winds into the region. The wet year composites indicate the opposite where the winds are strongly northerly (e) with almost no zonal wind anomaly (d). Figure 7(f) reiterates the corresponding vector winds which are northerly over the region that are driven by a high pressure anomaly area to the southwest of the region as reflected by the geopotential heights. These winds advect relatively warmer and humid tropical air into Free State that is forced to rise as they approach the Drakensberg uplands to the south. We hypothesize that the low-level northerlies would enhance the orographic effects of the Drakensberg highlands over the Free State Province, where the rainfall has been noted to generally increase with altitude. Therefore northerly wind anomalies are linked to wet events while southwesterly wind anomalies are linked droughts over the Free State region.

To illustrate the strong regional connection of the wind factor to the SPI, we present in Figures 8(a) and 8(b) the spatial correlation of the averaged Free State SPI with the surface zonal and meridional winds. The significant association with the two wind fields is quite conspicuous where the droughts are related to westerly and southerly wind anomalies while wet episodes are linked to the reverse wind anomalies. The impacts appear to weaken drastically towards the summit of the Drakensberg Mountains. This weakening demonstrates the visible impacts of the increasing altitude from the west and north of the mountains. Thus, despite the amount of moisture that is carried by the winds to determine the drought/wet episodes, the direction of the wind relative to the uplands also determines which place becomes the rain shadow and which does not.

3.3. Altitude Modified SPI Relationship with ENSO. The ENSO relationship with the JFM SPI for Free State is weak with an inverse correlation value of -0.29 and a $p$ value of 0.032 while that for OND SPI is relatively stronger with a value of -0.385 and a $p$ value of 0.004 . In Figure 9(a) we present the relationship between ENSO and the three clusters during OND and JFM. It is interesting to note that the relationship is strongly determined by the clusters in both cases hence signifying the impact of relief on the ENSO's influence on the extreme rainfall events. It is evident that 


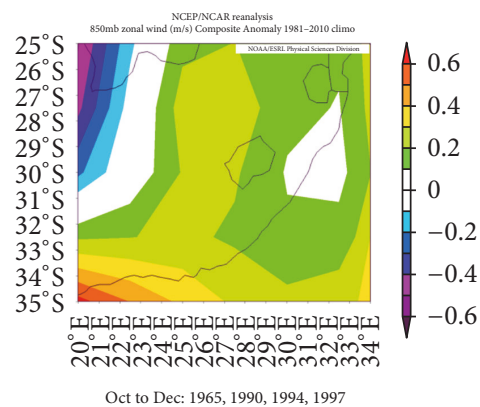

(a)

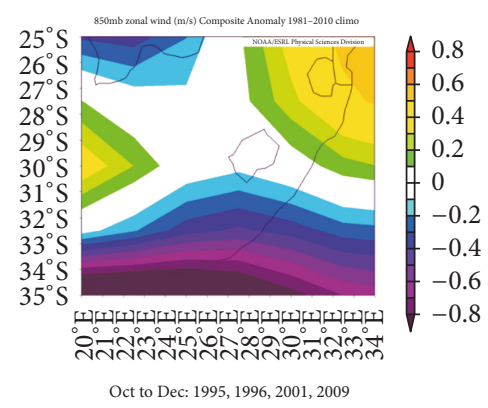

(d)

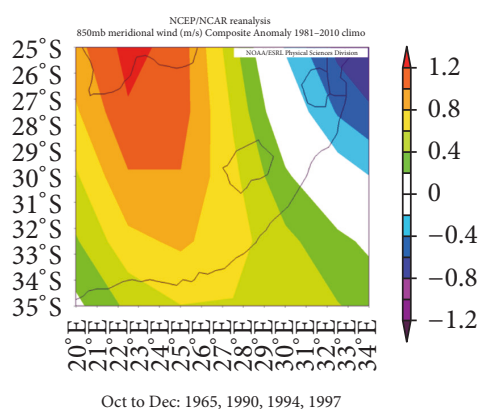

(b)

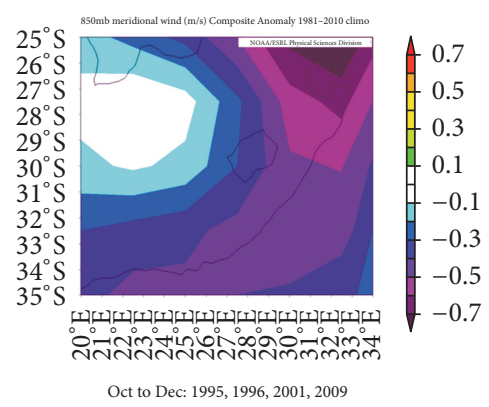

(e)

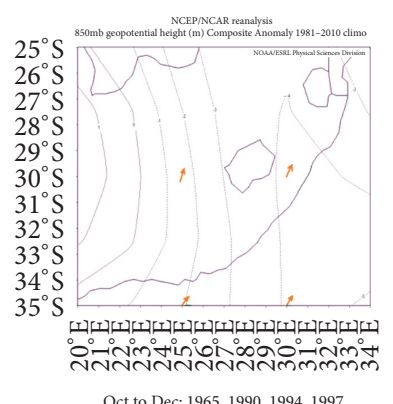

(c)

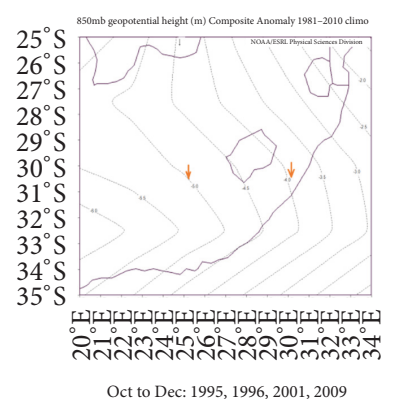

(f)

FIGURE 7: Zonal, meridional, and geopotential height anomalies for droughts (a), (b), and (c) and wet events (d), (e), and (f), respectively. Scalar winds are indicated in (c) and (f) with the years constituting the composites shown in the inserts.

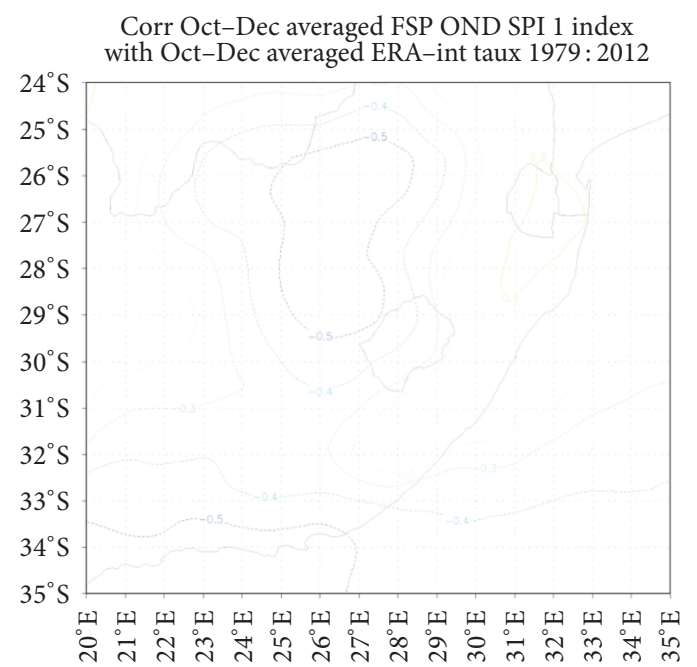

(a)

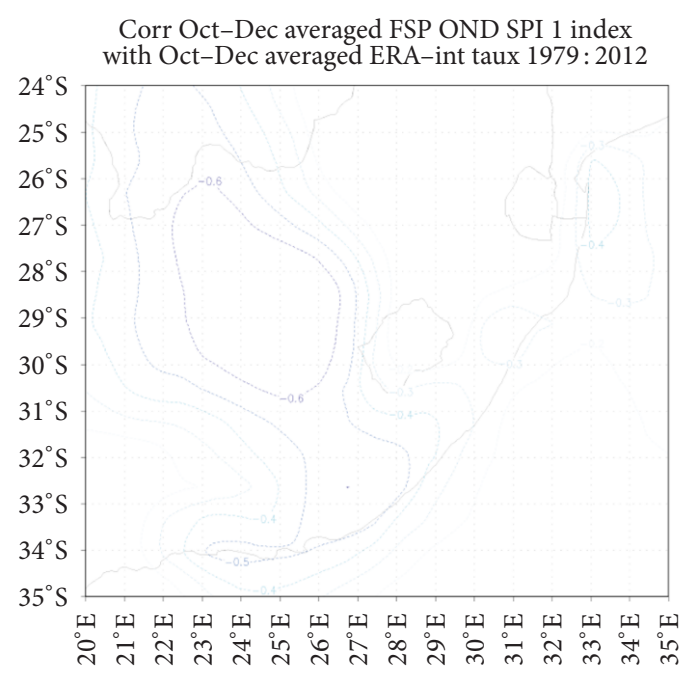

(b)

FIGURE 8: Spatial correlation of Free State OND SPI with (a) zonal surface winds and (b) meridional surface winds during OND for the period from 1960 to 2013. Tau- $x$ and tau- $y$ mean surface winds in the zonal and meridional direction, respectively.

ENSO's impacts are strongest in the lowlands but weakest over the highlands. Relief modifies the rainfall received at a place and the higher the altitude is, the more modification to rainfall occurs. Hence, this observation reiterates the important role played by relief in weakening ENSO's impacts on the rainfall events. It is, however, noted that the correlations are stronger for the OND than for the JFM period for all clusters. Figure 9(b) supports the observation that El Nino not only does impact more strongly on the OND than the JFM period but also shows a greater influence on Cluster 1 . As such the altitude for the Free State Province strongly demonstrates a robust relationship with ENSO.

\section{Conclusions}

The objective of the study was to assess the influence of altitude on drought severity and frequency in the Free State Province of South Africa. The study revealed the spatial 


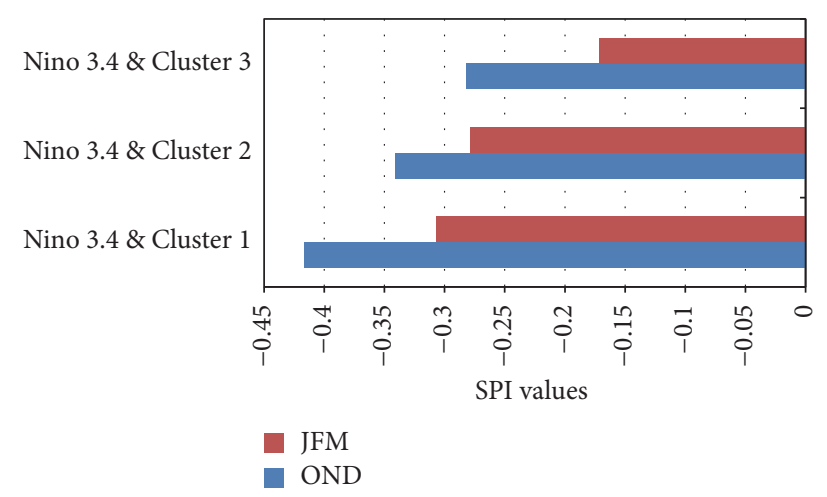

(a)

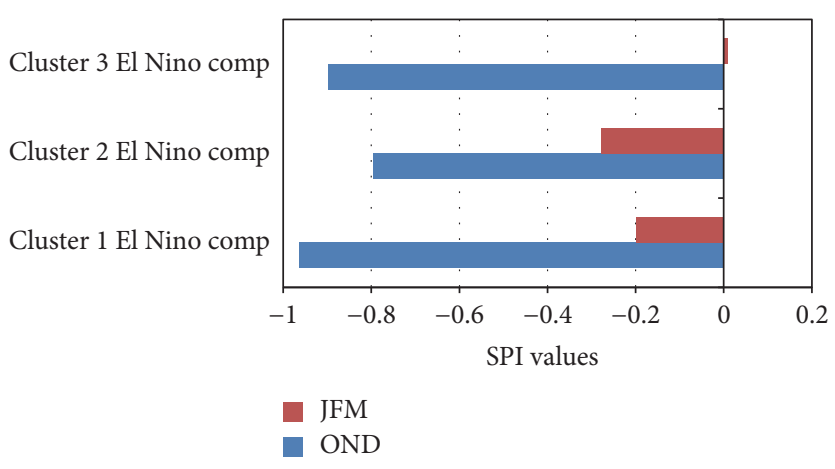

(b)

FIGURE 9: (a) Relationship between ENSO and the three clusters and (b) the El Nino composite SPI values for the three clusters during OND and JFM. The data is from 1960 to 2013 and the El Nino composites are comprised of the lowest Nino 3.4 values of 1965/66, 1972/73, 1982/83, $1987 / 1988,1991 / 92,1997 / 98$, and 2002/03.

heterogeneity in the SPI over Free State and showed that the factors governing drought interannual variability varied markedly within the region and from the early part of the rainfall season to late subseason. Highland areas (Cluster 3) have the highest frequency of droughts although more extreme droughts occurred in the extreme western low-lying regions (Cluster 1). Significant differences among clusters during the early summer season, OND, were observed. These results are evidence that altitudinal variations have a significant impact on drought severity during the early summer season but not in the late summer season. The study targeted droughts of SPI $\leq-1.282$. The relationship between ENSO and SPI indicates stronger correlations for the early summer subseason than for the late summer subseason. The local impacts of ENSO are strongly impacted on by altitude where the lower regions are stronger but weaker at higher altitudes. Mountains are an important ecosystem resource that warrants effective conservation strategies for what transpires in the region govern numerous economic activities often well beyond the boundaries of the mountain areas themselves. It is from this perspective that Disaster Management agencies need to consider the vulnerability of the province to drought conditions.

\section{Conflicts of Interest}

The authors declare that there are no conflicts of interest.

\section{Acknowledgments}

The authors wish to acknowledge the University of Free State Afromontane Research Unit (ARU) for the financial support received. The work was carried out using Climate Research Unit datasets provided on the Climate Explorer website.

\section{References}

[1] O. Zolina, C. Simmer, S. K. Gulev, and S. Kollet, "Changing structure of european precipitation: longer wet periods leading to more abundant rainfalls," Geophysical Research Letters, vol. 37, no. 6, Article ID L06704, 2010.

[2] A. S. Singh and M. B. Masuku, "Sampling techniques determination of sample size in applied statistics research: an overview," International Journal of Commerce and Management, vol. II, no. 11, pp. 1-22, 2014.

[3] N. Batisani and B. Yarnal, "Rainfall variability and trends in semi-arid Botswana: implications for climate change adaptation policy," Applied Geography, vol. 30, no. 4, pp. 483-489, 2010.

[4] IPCC, Climate Change 2014 Synthesis Report.Contribution of Working Groups I, II and III to the Fifth Assessment Report of the Intergovernmental Panel on Climate Change, IPCC, Geneva, Switzerland, 2014.

[5] C. A. Costa and D. Santos, "Trends in indices for extremes in daily air temperature over Utah, USA," Revista Brasileira de Meteorologia, vol. 261, pp. 19-28, 2011.

[6] A. Moberg and P. D. Jones, "Trends in indices for extremes in daily temperature and precipitation in central and western Europe, 1901-99," International Journal of Climatology, vol. 25, no. 9, pp. 1149-1171, 2005.

[7] M. J. Zhang, J. Y. He, B. L. Wang et al., "Extreme drought changes in Southwest China from 1960 to 2009," Journal of Geographical Sciences, vol. 23, no. 1, pp. 3-16, 2013.

[8] J. Esper, D. Frank, U. Büntgen, A. Verstege, J. Luterbacher, and E. Xoplaki, "Long-term drought severity variations in Morocco," Geophysical Research Letters, vol. 34, no. 17, Article ID L17702, 2007.

[9] S. M. Vicente-Serrano, S. Beguería, L. Gimeno et al., "Challenges for drought mitigation in Africa: the potential use of geospatial data and drought information systems," Applied Geography, vol. 34, no. 3, pp. 471-486, 2012.

[10] T. Palmer and A. Ainslie, Country Pasture/Forage Resource Profiles South Africa, FAO, 2006.

[11] E. Bryant, Natural Hazards, Cambridge University Press, New York, NY, USA, 2004.

[12] S. Hastenrath, "Variations of East African climate during the past two centuries," Climatic Change, vol. 50, no. 1-2, pp. 209217, 2001.

[13] Z. Zuo and J. Oerlemans, "Numerical modelling of the historic front variation and the future behaviour of the Pasterze glacier, Austria," Annals of Glaciology, vol. 24, pp. 234-241, 1997. 
[14] L. Halada, "Ecosystem services of mountains-an urgent research area," in Landscape Ecology, 2010.

[15] G. M. MacDonald and A. H. Tingstad, "Recent and multicentennial precipitation variability and drought occurrence in the Uinta Mountains region, Utah," Arctic, Antarctic, and Alpine Research, vol. 39, no. 4, pp. 549-555, 2007.

[16] S. Shahid and M. K. Hazarika, "Groundwater drought in the northwestern districts of Bangladesh," Water Resources Management, vol. 24, no. 10, pp. 1989-2006, 2010.

[17] E. Viste, D. Korecha, and A. Sorteberg, "Recent drought and precipitation tendencies in Ethiopia," Theoretical and Applied Climatology, vol. 112, no. 3-4, pp. 535-551, 2013.

[18] A. Zargar, R. Sadiq, B. Naser, and F. I. Khan, "A review of drought indices," Environmental Reviews, vol. 19, no. 1, pp. 333349, 2011.

[19] M. V. K. Sivakumar, R. P. Motha, D. A. White, and D. A. Wood, "Quantification of agricultural drought for effective drought mitigation and preparedness: key issues and challenges," in Agricultural Drought Indices Proceedings of a WMO Expert Meeting on Agricultural Drought Indices, p. 15, 2011.

[20] S. M. Vicente-Serrano, O. Chura, J. I. López-Moreno et al., "Spatio-temporal variability of droughts in Bolivia: 1955-2012," International Journal of Climatology, vol. 35, no. 10, pp. 30243040, 2015.

[21] P. Angelidis, F. Maris, N. Kotsovinos, and V. Hrissanthou, "Computation of drought index SPI with alternative distribution functions," Water Resources Management, vol. 26, no. 9, pp. 2453-2473, 2012.

[22] S. Beguería, S. M. Vicente-Serrano, F. Reig, and B. Latorre, "Standardized precipitation evapotranspiration index (SPEI) revisited: parameter fitting, evapotranspiration models, tools, datasets and drought monitoring," International Journal of Climatology, vol. 34, no. 10, pp. 3001-3023, 2014.

[23] H. Wu, M. D. Svoboda, M. J. Hayes, D. A. Wilhite, and F. Wen, "Appropriate application of the standardized precipitation index in arid locations and dry seasons," International Journal of Climatology, vol. 27, no. 1, pp. 65-79, 2007.

[24] M. Hayes, M. Svoboda, N. Wall, and M. Widhalm, "The lincoln declaration on drought indices: universal meteorological drought index recommended," Bulletin of the American Meteorological Society, vol. 92, no. 4, pp. 485-488, 2011.

[25] C. Körner, J. Paulsen, and E. M. Spehn, "A definition of mountains and their bioclimatic belts for global comparisons of biodiversity data," Alpine Botany, vol. 121, no. 2, pp. 73-78, 2011.

[26] C. T. Agnew, "Using the SPI to identify drought," Drought Network News, vol. 12, no. 1, pp. 1-12, 2000.

[27] D. Manatsa, G. Mukwada, E. Siziba, and T. Chinyanganya, "Analysis of multidimensional aspects of agricultural droughts in Zimbabwe using the Standardized Precipitation Index (SPI)," Theoretical and Applied Climatology, vol. 102, no. 3, pp. 287-305, 2010.

[28] T. B. Mckee, N. J. Doesken, and J. Kleist, "The relationship of drought frequency and duration to time scales," in Proceedings of the Eighth Conference on Applied Climatology, pp. 17-22, 1993.

[29] C. Cook, C. J. C. Reason, and B. C. Hewitson, "Wet and dry spells within particularly wet and dry summers in the South African summer rainfall region," Climate Research, vol. 26, no. 1, pp. 17-31, 2004.

[30] D. J. Cannon, D. J. Brayshaw, J. Methven, P. J. Coker, and D. Lenaghan, "Using reanalysis data to quantify extreme wind power generation statistics: a 33 year case study in Great Britain," Journal of Renewable Energy, vol. 75, pp. 767-778, 2015.
[31] M. V. K. Sivakumar, "Agricultural Drought-WMO Perspectives," 2011.

[32] B. Saghafian and S. R. Bondarabadi, "Validity of regional rainfall spatial distribution methods in mountainous areas," Journal of Hydrologic Engineering, vol. 13, no. 7, pp. 531-540, 2008.

[33] B. S. Everitt, S. Landau, M. Leese, and D. Stahl, An Introduction to Classification and Clustering, John Wiley \& Sons, 2011.

[34] A. T. Singleton and C. J. C. Reason Jr., "Variability in the characteristics of cut-off low pressure systems over subtropical southern Africa," International Journal of Climatology, vol. 27, no. 3, pp. 295-310, 2007.

[35] L. L. Dyson and J. Van Heerden, "A model for the identification of tropical weather systems over South Africa," Water SA, vol. 28, no. 3, pp. 249-258, 2002.

[36] A. A. Akinsanola and K. O. Ogunjobi, "Recent homogeneity analysis and long-term spatio-temporal rainfall trends in Nigeria," Theoretical and Applied Climatology, vol. 128, no. 1-2, pp. 275-289, 2017.

[37] W. Nel, D. A. Reynhardt, and P. D. Sumner, "Effect of altitude on erosive characteristics of concurrent rainfall events in the northern kwazulu-natal drakensberg," Water $S A$, vol. 36, no. 4, pp. 509-512, 2010. 

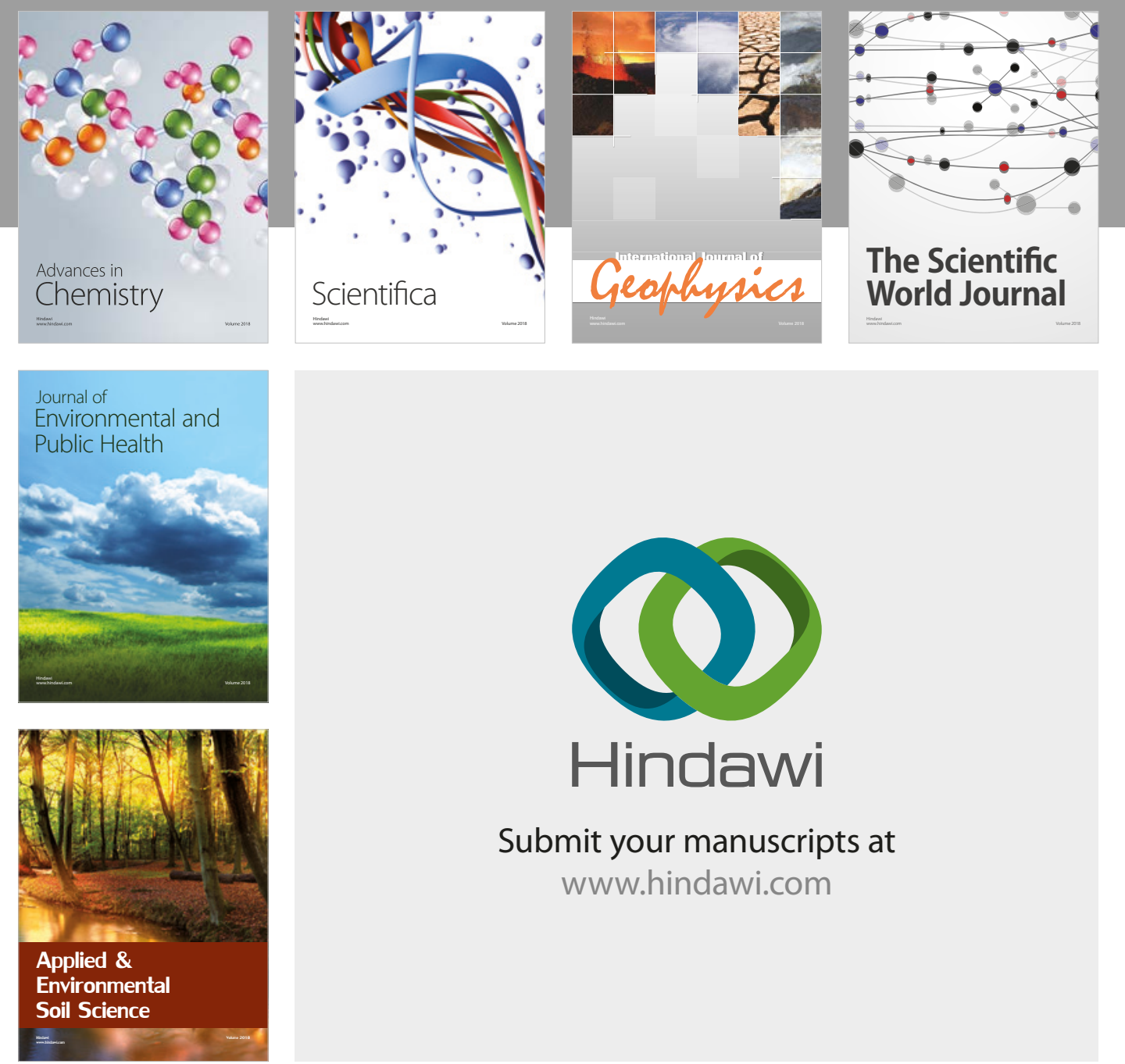

The Scientific

\section{World Journal}
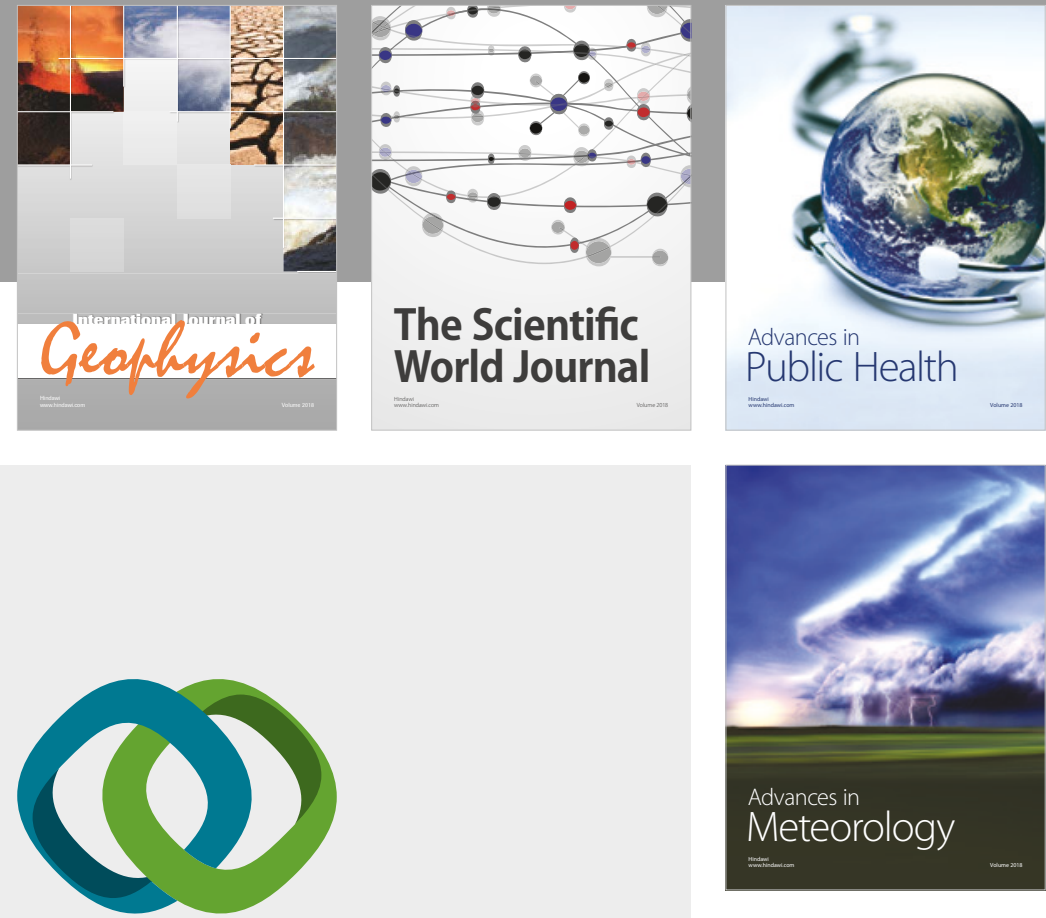

Advan

Public Health

\section{Hindawi}

Submit your manuscripts at

www.hindawi.com
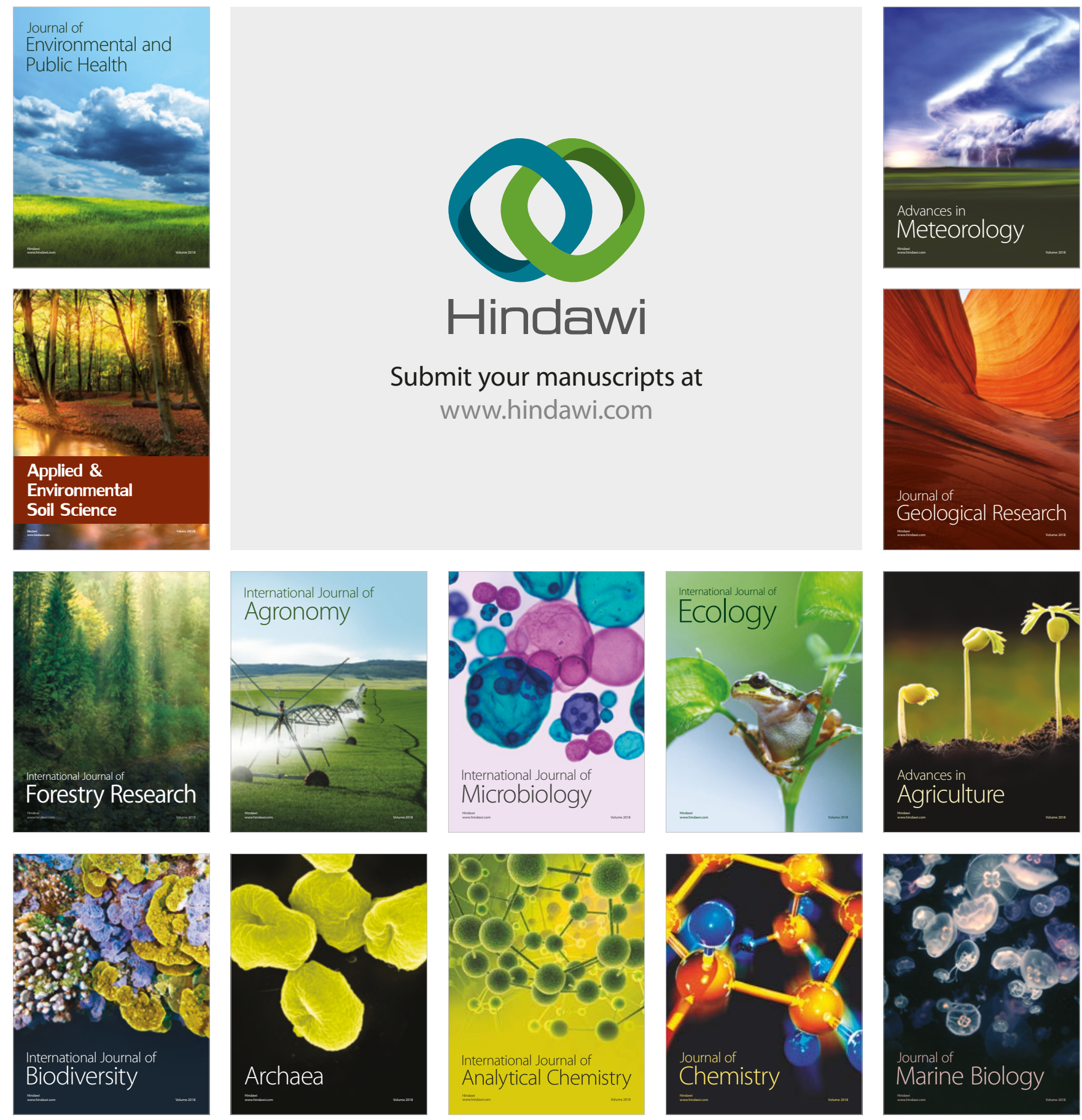